\title{
DESKRIPSI TENTANG KEAMANAN DI GEDUNG DAN JALANAN KOTA KUALA LUMPUR
}

\author{
Ahmad Mustanir \\ STISIP Muhammadiyah Rappang \\ ahmadmustanir74@gmail.com
}

\begin{abstract}
Menarik melihat gedung-gedung perkantoran dan jalanan di Kota Kuala Lumpur Malaysia. Gedung-gedung perkantoran yang demikian besar dan megah tetapi sangat jarang kami melihat petugas keamanan baik polisi ataupun keamanan internal (satpam) yang berseragam. Hanya di tempat-tempat tertentu terdapat keamanan internal (satpam) yang berseragam itupun jumlahnya tidak terlalu mencolok seperti di Gedung Mahkamah Kehakiman yang kelihatan hanya bertugas untuk memeriksa barang bawaan pengunjung gedung/sidang. Dengan jumlah personel keamanan berseragaman yang minim tetapi tingkat keamanan dan kenyamanan pengunjung terasa sangat baik. Ini lah titik perbedaan yang mendasar di bandingkan dengan kota besar di Indonesia.
\end{abstract}

Keywords : Gedung, Jalanan, Keamanan 


\section{DESKRIPSI SAYA TENTANG : \\ KEAMANAN/SEKURITI DI GEDUNG DAN JALANAN KOTA KUALA LUMPUR}

Menarik melihat gedung-gedung perkantoran dan jalanan di Kota Kuala Lumpur Malaysia. Gedung-gedung perkantoran yang demikian besar dan megah tetapi sangat jarang kami melihat petugas keamanan baik polisi ataupun keamanan internal (satpam) yang berseragam. Hanya di tempat-tempat tertentu terdapat keamanan internal (satpam) yang berseragam itupun jumlahnya tidak terlalu mencolok seperti di Gedung Mahkamah Kehakiman yang kelihatan hanya bertugas

untuk memeriksa barang bawaan pengunjung gedung/sidang. Dengan jumlah personel keamanan berseragaman yang minim tetapi tingkat keamanan dan kenyamanan pengunjung terasa sangat baik. Ini lah titik perbedaan yang mendasar di bandingkan dengan kota besar di Indonesia (Mustanir \& Jusman, 2016) (Mustanir, Yasin, Irwan, \& Rusdi, 2018) (Mustanir \& Jaya, 2016) (Mustanir, Abadi, \& Nasri, 2016) (Mustanir \& Darmiah, 2016) (Mustanir \& Lubis, 2017a) (Akhmad, Mustanir, \& Ramadhan, 2018) (Razak, Dahong, Ahmad, Dema, \& Mustanir, 2018) (Mustanir \& Yasin, 2018) (Mustanir, Ahmad; Abadi, 2016) (Barisan, Ramadhan, \& Mustanir, 2017) (Mustanir \& Rusdi, 2019a) (Mustanir, 2016b) (Mustanir, Justira, Sellang, \& Muchtar, 2018) (Mustanir, Ahmad; Barisan, Barisan; Hamid, 2017) (Mustanir \& Lubis, 2017b) (Mustanir \& Razak, 2017) (Mustanir, Ali, \& Yasin, 2018) (Mustanir \& Rusdi, 2019b) (Damis Dadda, Mustanir, Nilwana, \& Ahmad, 2019) (Mustanir \& Rusdi. Muhammad, 2019) (Ramadhan \& Mustanir, 2017) (Mustanir, n.d.) (Damis Dadda et al., 2019) (Irwan, Latif, Sofyan, Mustanir, \& Fatimah, 2019) (Latif, Irwan, Rusdi, Mustanir, \& Sutrisno, 2019) (Mustanir, 2016a) (Mustanir, 2015) (Mustanir, Ali, et al., 2018)

Di jalanan, keberadaan polisi lalu lintas selama 9 (sembilan) hari kami berada di Kuala Lumpur sangat sulit di temui. Hanya pada saat berkunjung ke PWTC tempat pelaksanaan Book Fair saya baru melihat adanya polisi lalu lintas di jalanan, itupun jumlahnya hanya 2 (dua) orang.

Nampaknya sistem keamanan pada gedung-gedung perkantoran di Kuala Lumpur lebih banyak menggunakan Visitor Management System (VMS), Access Control dan CCTV dengan sistem keamanan yang terintegrasi. Ini nampak di gedung Mahkamah Kehakiman saat kami akan memasuki ruang salah seorang pejabat yakni Tuan Akhiruddin dimana untuk memasuki ruangan harus menggunakan Access Control/ Visitor Management System (VMS) yang di pegang oleh 
masing-masing staff atau pejabat, sehingga tidak adanya orang lain yang masuk tanpa seizin pemilik.

Sepengetahuan saya Visitor Management System adalah sebuah sistem yang dipergunakan untuk melakukan management tamu atau pengunjung, yang biasanya diterapkan pada high rise building, perkantoran, instansi umum atau pemerintahan yang fungsi utamanya adalah untuk mengurangi resiko yang tidak diiinginkan, baik berupa unsur kriminal, terorisme, dan tindakan yang bersifat negatif lainya. Visitor Management System merupakan sebuah cara terbaik untuk saat ini untuk mencegah sesuatu yang tidak diinginkan, yang ditempatkan pada porsi membantu sistem keamanan dan pengamanan sebuah instansi yang sudah ada sebelumnya, tetapi tidak untuk mengganti yang sudah ada. Inilah nampaknya yang banyak di gunakan di perkantoran di Kuala Lumpur.

Selain itu penggunaan CCTV (Closed Circuit Television) adalah hal yang paling sering saya temukan. Hampir seluruh gedung perkantoran, jalanan dan sarana pelayanan publik di pasangi CCTV. Hal ini semua yang menurut penilaian saya sehingga jumlah aparat berseragam nampak minim tetapi tetap memberikan keamanan yang sangat baik.

Khusus untuk jalanan raya hampir semua petunjuk/marka rambu lalu lintas berada dalam keadaan baik dan baru, serta tampilan huruf yang sangat besar sehingga sangat mudah di baca dan di pahami walau dalam keadaan jarak yang jauh. Penyediaan marka rambu lalu lintas seperti ini akan memberikan rasa aman dan nyaman bagi pengguna jalan. (Foto-foto lain terlampir)

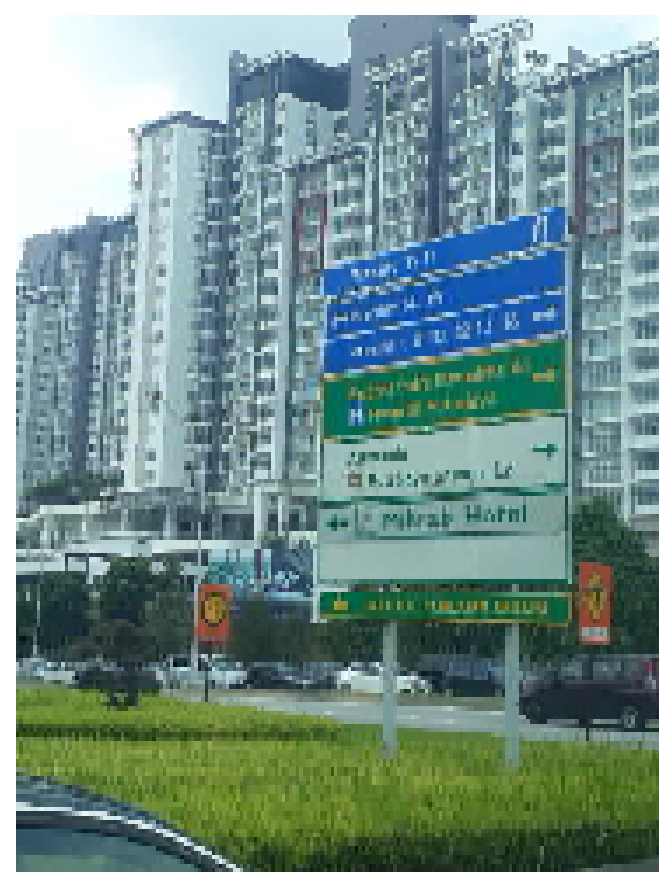


DESKRIPSI SAYA TENTANG :

SEMANGAT DAN TANGGUNG JAWAB

(Hazizah \& Co - Advocates \& Solicitors,

Peguambela \& Peguamcara

Peguam Syarie)

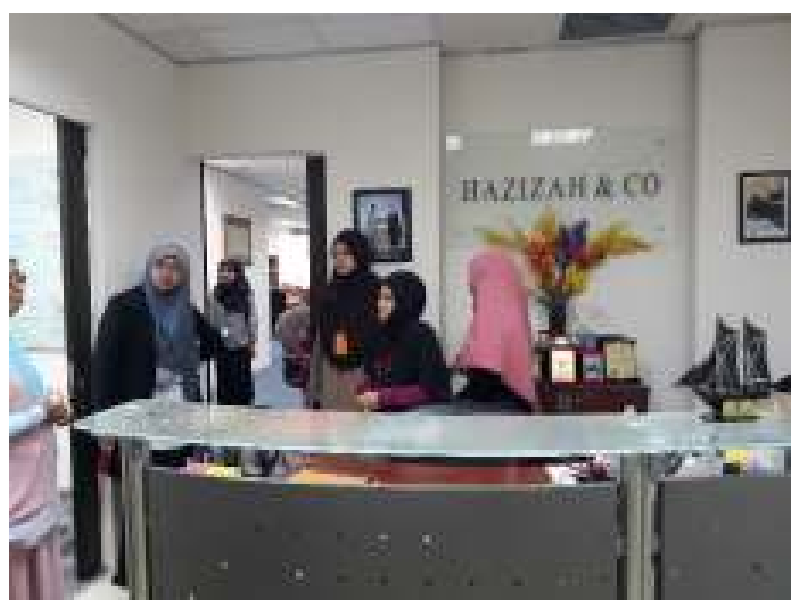

Ada perasaan kagum dan takjub untuk pertamakali melihat hal unik sebuah kantor yang bergerak di dunia yang bagi saya cukup 'keras' yaitu dunia hukum. Dimana seluruh staff nya keseluruhan terdiri dari para wanita. Entah apakah ini hanya ada di kantor tersebut, ataukah juga terdapat dikantor lainnya di negara Malaysia atau negara saya Indonesia. Yang paling penting dari itu adalah saya melihat keseluruhan staff sangat bersemangat dan bertanggung jawab atas tugas yang diberikan oleh pimpinan, misalnya tidak seorang pun yang meninggalkan kantor di luar jam istirahat dan jam pulang.

Pimpinan juga demikian memiliki rasa semangat dan tanggung jawab. Ibu Datin dalam memberikan pelayanan pada kami pun diluar dugaan saya. Banyak hal-hal yang tidak ada dalam pikiran kami, tetapi menjadi sebuah terobosan baru dan pengalaman yang berharga bagi kami dalam kerja sama ini. Seperti memberikan kesempatan ke kantor-kantor pelayanan publik dan memberikan link dalam kerjasama baru lainnya seperti MOU yang di tanda tangani oleh Pimpinan Panti Asuhan Sejati Rappang dengan Al Madinah Foundation. (Foto-foto lain terlampir)

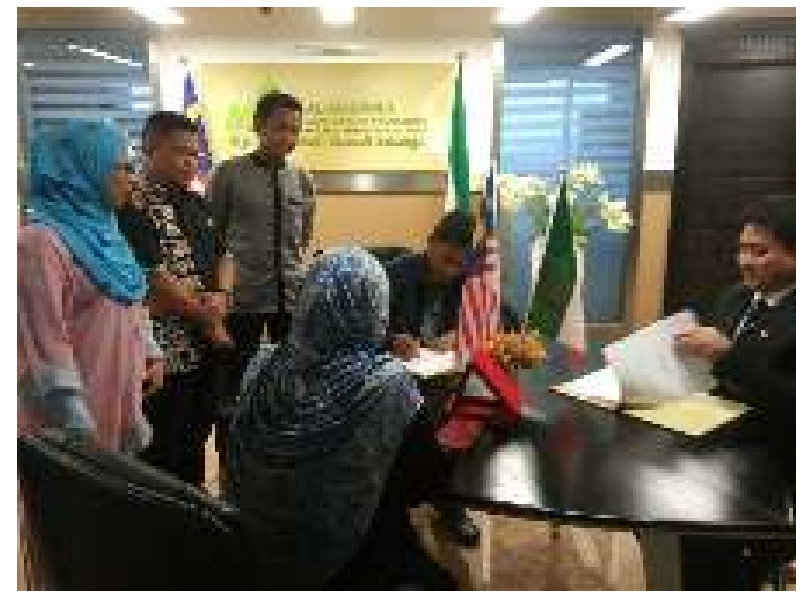




\section{REFERENSI}

Akhmad, I., Mustanir, A., \& Ramadhan, M. R. (2018). Pengaruh Pemanfaatan Tekhnologi Informasi dan Pengawasan Keuangan Daerah Terhadap Kualitas Laporan Keuangan Kabupaten Enrekang. In Prosiding Konferensi Nasional Ke-7 Asosiasi Program Pascasarjana Perguruan Tinggi Muhammadiyah Aisyiyah (APPPTMA). Jilid 2. Sosial Politik dan Ekonomi (pp. 89-103). Retrieved from http://asosiasipascaptm.or.id/index.php/publikasi/konferensi-appptm-ke-7-meningkatkankualitas-dan-kuantitas-jurnal-ilmiah

Barisan, B., Ramadhan, M. R., \& Mustanir, A. (2017). Sidenreng Rappang Versus Masyarakat Ekonomi Asean. In The 2nd Journal of Government and Politics International Conference (Vol. II, pp. 258 - 262). Yogyakarta: Penerbit Program Pascasarjana Universitas Muhammadiyah Yogyakarta. Retrieved from http://jksg.umy.ac.id/proceeding-2nd-jgp/

Damis Dadda, A., Mustanir, A., Nilwana, A., \& Ahmad, J. (2019). Pengaruh Kepemimpinan Lurah Perempuan Terhadap Stabilitas Kamtibmas Di Kelurahan Rappang Kabupaten Sidenreng Rappang. In Konferensi Nasional Ke-8 Asosiasi Program Pascasarjana Perguruan Tinggi Muhammadiyah Aisyiyah (APPPTMA) (pp. 378-383). Medan: Program Pascasarjana Universitas Muhammadiyah Yogyakarta. Retrieved from http://asosiasipascaptm.or.id/index.php/publikasi/prosiding-konferensi-nasional-appptmake-8

Irwan, I., Latif, A., Sofyan, S., Mustanir, A., \& Fatimah, F. (2019). Gaya Kepemimpinan, Kinerja Aparatur Sipil Negara dan Partisipasi Masyarakat Terhadap Pembangunan Di Kecamatan Kulo Kabupaten Sidenreng Rappang. MODERAT: Jurnal Ilmiah Ilmu Pemerintahan Universitas Galuh Ciamis, 5(1), 32-43. Retrieved from https://jurnal.unigal.ac.id/index.php/moderat/article/view/1900

Latif, A., Irwan, I., Rusdi, M., Mustanir, A., \& Sutrisno, M. (2019). Partisipasi Masyarakat Dalam Pembangunan Infrastruktur Di Desa Timoreng Panua Kecamatan Panca Rijang Kabupaten Sidenreng Rappang. MODERAT: Jurnal Ilmiah Ilmu Pemerintahan Universitas Galuh Ciamis, 5(1), 1-15. Retrieved from https://jurnal.unigal.ac.id/index.php/moderat/article/view/1898

Mustanir, Ahmad; Abadi, P. (2016). PARTISIPASI MASYARAKAT DALAM MUSYAWARAH RENCANA PEMBANGUNAN DI KELURAHAN KANYUARA KECAMATAN WATANG SIDENRENG KABUPATEN SIDENRENG RAPPANG. Jurnal Politik Profetik, 5(2), 247-261. Retrieved from http://journal.uinalauddin.ac.id/index.php/jpp/article/viewFile/4347/3986

Mustanir, Ahmad; Barisan, Barisan; Hamid, H. (2017). Participatory Rural Appraisal As The Participatory Planning Method Of Development Planning. In P. K. Nanang Haryono, Agie Nugroho Soegiono, Putu Aditya Ferdy Ariawantara (Ed.), Indonesian Association for Public Administration (IAPA) International Conference Towards Open Government: Finding the Whole Government Approach (pp. 77-84). Surabaya: The Faculty Of Social And Political Science Universitas Airlangga. Retrieved from http://conference.unair.ac.id/index.php/IAPA/iapa2017

Mustanir, A. (n.d.). Pemberdayaan Masyarakat Kewirausahaan. Retrieved from https://www.researchgate.net/publication/331311483_Pemberdayaan_Masyarakat_Kewirau sahaan

Mustanir, A. (2015). Pemberdayaan Masyarakat Berbasis Bina Desa. 
Mustanir, A. (2016a). Magang mahasiswa. Rappang. Retrieved from https://www.academia.edu/38492683/Panduan_magang_STISIP_Muhammadiyah_Rappang 2015_2016.pdf

Mustanir, A. (2016b). Perencanaan Mewujudkan Kehidupan Pemerintahan dan Sosial Yang Islami di Desa Tonrong Rijang Kabupaten Sidenreng Rappang. Prosiding Seminar Nasional, Reformasi Dan Inovasi Tata Kelola Pemerintahan, 289 - 307. Retrieved from https://www.researchgate.net/publication/330101808_Perencanaan_Mewujudkan_Kehidupa n_Pemerintahan_dan_Sosial_Yang_Islami_di_Desa_Tonrong_Rijang_Kabupaten_Sidenren g_Rappang

Mustanir, A., Abadi, P., \& Nasri, A. (2016). Participation of Ethnic Community Towani Tolotang in Deliberation of Development Plan. In International Conference on Ethics in Governance (ICONEG 2016) (Vol. 84, pp. 356 - 359). Makassar: Atlantis Press. https://doi.org/10.2991/iconeg-16.2017.79

Mustanir, A., Ali, A., \& Yasin, A. (2018). Transect on Participatory Development Planning in Sidenreng Rappang Regency. In IOP Conference Series: Earth and Environmental Science. Maka.

Mustanir, A., \& Darmiah, D. (2016). IMPLEMENTASI KEBIJAKAN DANA DESA DAN PARTISIPASI MASYARAKAT DALAM PEMBANGUNAN DI DESA TETEAJI KECAMATAN TELLU LIMPOE KABUPATEN SIDENRENG RAPPANG. Jurnal Politik Profetik, 4(2), 225-238. Retrieved from http://journal.uinalauddin.ac.id/index.php/jpp/article/view/2749

Mustanir, A., \& Jaya, I. (2016). PENGARUH KEPEMIMPINAN DAN BUDAYA POLITIK TERHADAP PERILAKU PEMILIH TOWANI TOLOTANG DI KECAMATAN MARITENGNGAE KABUPATEN SIDENRENG RAPPANG. Jurnal Politik Profetik, 4(1), 84-97. Retrieved from http://journal.uinalauddin.ac.id/index.php/jpp/article/view/2741\#

Mustanir, A., \& Jusman. (2016). IMPLEMENTASI KEBIJAKAN DAN EFEKTIVITAS PENGELOLAAN TERHADAP PENERIMAAN RETRIBUSI DI PASAR LANCIRANG KECAMATAN PITU RIAWA KABUPATEN SIDENRENG RAPPANG. Jurnal Ilmiah Akmen, 13(3), 542-558. Retrieved from https://e-jurnal.stienobelindonesia.ac.id/index.php/akmen/article/view/69

Mustanir, A., Justira, N., Sellang, K., \& Muchtar, A. I. (2018). Democratic Model On DecisionMaking At Deliberations Of Development Planning. International Conference on Government Leadership and Social Science (ICOGLASS). Demanding Governance Accountability and Promoting Democratic Leadership for Public Welfare Achievement, 110 -115. Retrieved from https://www.researchgate.net/publication/330090538_Democratic_Model_On_DecisionMaking_At_Deliberations_Of_Development_Planning

Mustanir, A., \& Lubis, S. (2017a). Participatory Rural Appraisal in Deliberations of Development Planning. International Conference On Democracy, Accountability, and Governance (ICODAG 2017) (Vol. 163). https://doi.org/10.2991/icodag-17.2017.60.

Mustanir, A., \& Lubis, S. (2017b). Participatory Rural Appraisal in Deliberations of Development Planning. In International Conference On Democracy, Accountability, and Governance (ICODAG 2017) (Vol. 163, pp. 316-319). Pekanbaru: Atlantis Press. https://doi.org/10.2991/icodag-17.2017.60.

Mustanir, A., \& Razak, M. R. R. (2017). Nilai Sosial Budaya Pada Partisipasi Masyarakat Etnik 
Towani Tolotang Dalam Musyawarah Rencana Pembangunan. In Prosiding Konferensi Nasional Ke-6 Asosiasi Program Pascasarjana Perguruan Tinggi Muhammadiyah Aisyiyah (APPPTMA) (pp. 1-7). Pare Pare: Program Pascasarjana Universitas Muhammadiyah Yogyakarta. Retrieved from http://asosiasipascaptm.or.id/index.php/publikasi/prosidingkonferensi-nasional-appptma-ke-6

Mustanir, A., \& Rusdi. Muhammad. (2019). Participatory Rural Appraisal (PRA) Sebagai Sarana Dakwah Muhammadiyah Pada Perencanaan Pembangunan Di Kabupaten Sidenreng Rappang. In Konferensi Nasional Ke-8 Asosiasi Program Pascasarjana Perguruan Tinggi Muhammadiyah Aisyiyah (APPPTMA) (pp. 378-383). Medan: Penerbit Program Pascasarjana Universitas Muhammadiyah Yogyakarta. Retrieved from http://asosiasipascaptm.or.id/index.php/publikasi/prosiding-konferensi-nasional-appptmake-8

Mustanir, A., \& Rusdi, M. (2019a). Participatory Rural Appraisal (PRA) Sebagai Sarana Dakwah Muhammadiyah Pada Perencanaan Pembangunan di Kabupaten Sidenreng Rappang. Prosiding Konferensi Nasional Ke-8 Asosiasi Program Pascasarjana Perguruan Tinggi Muhammadiyah Aisyiyah (APPPTMA). Medan. Retrieved from http://asosiasipascaptm.or.id/index.php/publikasi/prosiding-konferensi-nasional-appptmake-8

Mustanir, A., \& Rusdi, M. (2019b). Participatory Rural Appraisal (PRA) Sebagai Sarana Dakwah Muhammadiyah Pada Perencanaan Pembangunan di Kabupaten Sidenreng Rappang. Prosiding Konferensi Nasional Ke-8 Asosiasi Program Pascasarjana Perguruan Tinggi Muhammadiyah Aisyiyah (APPPTMA).

Mustanir, A., \& Yasin, A. (2018). Community Participation in Transect on Development Planning. Jurnal Ilmiah Ilmu Administrasi Publik: Jurnal Pemikiran Dan Penelitian Administrasi Publik (JIAP), 8(2), 137-146. https://doi.org/https://doi.org/10.26858/jiap.v8i2.7994

Mustanir, A., Yasin, A., Irwan, I., \& Rusdi, M. (2018). Potret Irisan Bumi Desa Tonrong Rijang Dalam Transect Pada Perencanaan Pembangunan Partisipatif. MODERAT: Jurnal Ilmiah Ilmu Pemerintahan, 4(4), 1-14. Retrieved from https://jurnal.unigal.ac.id/index.php/moderat/article/view/1775

Ramadhan, M. R., \& Mustanir, A. (2017). Sidenreng Rappang Versus Masyarakat Ekonomi Asean. Retrieved from http://jksg.umy.ac.id/wp-content/uploads/2017/08/Proceding-The2nd-Journal-of-Government-and-Politics-2017.compressed.pdf

Razak, M. R. R., Dahong, M., Ahmad, J., Dema, H., \& Mustanir, A. (2018). The Effect of Siri's Marriage on Government Administration. International Journal of Sciences: Basic and Applied Research (IJSBAR), 42(3), 171-184. Retrieved from http://gssrr.org/index.php?journal=JournalOfBasicAndApplied\&page=article\&op=view\&pa th $\% 5 \mathrm{~B} \% 5 \mathrm{D}=9484$ 